\title{
Public Health Nutrition
}

\section{Volume 23, 2020 ISSN: 1368-9800 journals.cambridge.org/phn}

Publishing, Production, Marketing, and Subscription Sales Office:

Cambridge University Press

Journals Fulfillment Department

University Printing House

Shaftesbury Road

Cambridge CB2 8BS

UK

For Customers in North America:

Cambridge University Press

1 Liberty Plaza

Floor 20, New York

NY 10006

USA

\section{Special sales and supplements}

This journal accepts advertising and inserts. We also provide bulk reprints of suitable papers to meet teaching or promotional requirements. The journal also publishes supplementary material including conference proceedings on behalf of academic and corporate sponsors. Please contact Sarah Maddox at Cambridge University Press for further details (email: smaddox@cambridge.org).

\section{Subscription information}

Public Health Nutrition is an international journal published 18 times per year by Cambridge University Press on behalf of the Nutrition Society. The online edition is available at

journals.cambridge.org/PHN, with free table of contents alert (upon registration).

\section{Annual subscription rates}

Volume 23, 2020 (18 issues):

Internet/print package: £1391/\$2669 Americas only/€2230 EU only Internet only: $11007 / \$ 1911$ Americas only/€1601 EU only

Any supplements to this journal published in the course of the annual volume are normally supplied to subscribers at no extra charge.

Claims for non-receipt of journal issues will be considered on their merit and only if the claim is received within six months of publication. Replacement copies supplied after this date will be chargeable.

Advertising: The Nutrition Society is willing to include advertisements in its journals. However, it will retain the right to make decisions on which advertisements are acceptable and which are not, and will not be obliged to give reasons to prospective advertisers for its decisions. The appearance of an advertisement in the Society's journals does not imply endorsement by the Society. For further details, please contact Cambridge University Press.

Back volumes will be available in due course. Please contact Cambridge University Press for further information.

US POSTMASTERS: Please send address corrections to Cambridge University Press

1 Liberty Plaza

Floor 20, New York

NY 10006

USA

Notes for Authors are available from the publisher at the given address and can be found inside the back cover.

Offprints: The author (or main author) of an accepted paper will receive a free PDF of their paper. Additional offprints are available for a fee and must be ordered at proof stage. No page charges are levied by this journal.

Copyright: As of 1 January 2001 the copyright of all articles submitted to Public Health Nutrition are retained by the authors or their institutions. For articles prior to this date permission for reproduction of any part of the journal (text, figures, tables or other matter) in any form (on paper, microfiche or electronically) should be sought directly from the Society, at: The Editorial Office, The Nutrition Society, 10 Cambridge Court, 210 Shepherds Bush Road, Hammersmith, London, W6 7NJ, UK.

Disclaimer: The information contained herein, including any expression of opinion and any projection or forecast, has been obtained from or is based upon sources believed by us to be reliable, but is not guaranteed as to accuracy or completeness. The information is supplied without obligation and on the understanding that any person who acts upon it or otherwise changes his/her position in reliance thereon does so entirely at his/her own risk. Neither the Society, nor Cambridge University Press accepts responsibility for any trade advertisement included in this publication.

This journal issue has been printed on FSC-certified paper and cover board. FSC is an independent, non-governmental, not-for-profit organization established to promote the responsible management of the world's forests. Please see www.fsc.org for information. Typeset by Macmillan India Limited, Bangalore, India and Printed in Europe by Bell and Bain, Glasgow.

Public Health Nutrition is covered in Science Citation Index Expanded (Web of Science), Current Contents, Agriculture, Biology \& Environmental Sciences, Current Contents, Clinical Medicine, CAB ABSTRACTS ${ }^{\mathbb{R}}$, Global Health, Index Medicus ${ }^{\circledR}$ (MEDLINE ${ }^{\circledR}$ ), EMBASE, Excerpta Medica, BIOSIS ${ }^{\circledR}$ Database and CINAHL ${ }^{\circledR}$ Database Public Health Nutrition participates in the following initiatives: HINARI by WHO and AGORA by FAO. 
Public Health Nutrition (PHN) provides a forum for the presentation of original research findings and high quality reviews of key topics, and for discussion of and debate on of current issues and controversies. It also publishes special issues on major topics of interest. Our field includes research, scholarship, and discussions on public health nutrition, that take a population, health promoting and preventive approach. Papers that do not have this emphasis may be directed to more appropriate journals. Potential contributors are encouraged to read the aims and scope of the journal, and to note and follow the guidelines set out below.

\section{Content:}

- Original research findings and scientific reviews are published as full papers usually less than 5000 words, not including the abstract, references, tables, figures and acknowledgements.

- Editorials express the opinion of the journal, as represented by its central editorial team, on topics judged by them to be important. Editorials, including guest editorials, are usually co-ordinated and developed by the editorial team.

- Position papers, including declarations and other statements of policy, may be invited or unsolicited.

- Invited commentaries and book reviews are expressions of opinion on a topical subject. These are commissioned by the members of the editorial team.

- Letters to the Editors are usually in response to material published in $P H N$. Submissions are sent to the author for comment and, when possible, published together with the author's reply.

Submission: PHN operates an online submission and reviewing system. All manuscripts should be submitted to http:// mc.manuscriptcentral.com/phnutr. Please contact the Editorial Office on phn.edoffice@cambridge.org regarding any other types of submission.

Refereeing: Review articles and articles reporting original research are subject to external review by two or more referees who evaluate manuscripts based on their importance, relevance, and originality. Authors are asked to submit names and contact details (including email address) of up to four potential referees. All other contributions (editorials, position papers, invited commentaries, book reviews, and letters to the Editors) undergo an internal review process by at least two members of the editorial team. Invited commentaries and book reviews may also be checked externally as necessary to avoid technical errors and to improve salience.

Copyright: At the time of acceptance, authors will be asked to provide a completed copy of the 'Licence to Publish' (in lieu of copyright transfer), available at https://www.nutritionsociety. $\mathrm{org} /$. It is the author's responsibility to obtain written permission to reproduce any material (including text and figures) that has appeared in another publication.

Preparation of manuscripts: Please refer to the full Directions to Contributors on our website (http://www.nutritionsociety. org). Manuscripts should be in clear and concise English, and spelling should follow the Oxford English Dictionary. For authors whose native tongue is not English, in-house editorial attention to their contributions will improve clarity. On acceptance, all contributions are subject to editorial amendment to conform to house style. Manuscripts should be prepared in a common word processing package (Word for Windows is preferred) in Times New Roman or other common typeface, prepared with doublespaced text, at least $2 \mathrm{~cm}$ margins, and page and line numbers. Standard abbreviations and SI units must be used.

\section{Disclosure of financial support and any competing}

interests. The submission must include a statement within an Acknowledgements section reporting any competing interests (financial and non-financial), all sources of funding, and the nature of the contribution of each author to the manuscript. If there are no competing interests, this must be stated. Authors are asked to provide this information during the submission process and should not include it as part of the manuscript to allow for double-blind reviewing.

\section{Arrangement of papers:}

1. Title page should include the article title, author(s), affiliation(s), up to eight keywords, one author identified for correspondence (with full postal address, telephone and fax numbers, and email address), and a running title of up to 45 characters. The title page should be submitted online as a separate cover letter, not as part of the manuscript, to enable double-blind reviewing.

2. Abstract should be structured, usually using the following internal headings: Objective, Design, Setting, Subjects, Results, Conclusions. Abstracts should be intelligible without reference to text or figures and should not exceed 250 words.

3. Text should be divided under headings (typically to include Introduction, Methods, Results, Discussion and Conclusions), and sub-headings as appropriate. Conclusions should include recommendations that derive from the research and that are concrete, feasible, and potentially effective. Emphasising that more research is needed is usually not necessary unless there is specific reason to say so. All submissions must include a statement that the research was conducted in accordance with guidelines laid down by the Declaration of Helsinki and approved by an ethics review committee.

4. Acknowledgements (sources of funding, competing interests declaration, authorship responsibilities, acknowledgements) should be provided during the submission process, not as part of the manuscript.

5. References should be in Vancouver style. Please refer to the full Directions to Contributors.

6. Tables should be reduced to the simplest form and should not be used where text or figures give the same information. Each table must be accompanied by a clear and concise caption that is comprehensible without reference to the text. Longer tables may be published online only.

7. Figures should be numbered, and legends should be provided. Each figure, with its legend, should be comprehensible without reference to the text and include definitions of abbreviations.

Proofs: Correspondence and proofs for correction will be emailed to the first named author unless otherwise indicated. The author will receive a PDF proof for checking. It is important that proofs be returned promptly. Authors may be charged for any alterations in excess of $10 \%$ of original setting.

Offprints: The corresponding author will receive a PDF of the published paper free of charge. Offprints are available to purchase and must be ordered before publication. 


\section{PUBLIC HEALTH NUTRITION, VOLUME 23 - NUMBER 16}

\section{Monitoring and surveillance}

Differences in the sugar content of fast-food products across three countries Nicole Lewis, Qiushi Huang, Patrick Merkel, Dong Keun Rhee and Allison C Sylvetsky

Trends in sugar-sweetened beverage consumption among California children Amy L Beck, Suzanna Martinez, Anisha I Patel and Alicia Fernandez

Reformulation of sugar contents in Canadian prepackaged foods and beverages between 2013 and 2017 and resultant changes in nutritional composition of products with sugar reductions

Jodi T Bernstein, Anthea K Christoforou, Madyson Weippert and Mary R L'Abbé

\section{Assessment and methodology}

Comparison of methodological quality between the 2007 and 2019 Canadian dietary guidelines

Zhaoli Dai, Cynthia M Kroeger, Mark Lawrence,

Gyorgy Scrinis and Lisa Bero

Estimating energy expenditure of headhauling water and grain grinding from heart rate monitor measurements in northern Mozambique Kory C Russel, Matthew P Buman, Jennifer Davis and William L Haskell

Optimal cut-off points for waist circumference in the definition of metabolic syndrome in Chile Fanny Petermann-Rocha, María Adela Martínez-Sanguinetti, Frederick K Ho, Carlos Celis-Morales and Alonso Pizarro on behalf of ELHOC Research Group

\section{Nutritional status and body composition}

Differentiating effects of socio-economic factors on relative weight and nutritiona status in Polish schoolchildren across intergenerational changes

Natalia Nowak-Szczepanska,

Aleksandra Gomula and Slawomir Koziel

Low serum 25-hydroxyvitamin D levels are associated with liver injury markers in the US adult population Xiaowei He, Cheng Xu, Zheng-Hong Lu, Xiao-Zheng Fang, Juan Tan and Yingiian Song

Nutrient and food group intakes and skeletal muscle index in the Japanese elderly: a cross-sectional analysis of the NHNS 2017

Chika Okada, Emiko Okada and

Hidemi Takimoto

\section{Nutrition communication}

The heuristics that guide healthiness perception of ultra-processed foods: a qualitative exploration Leandro Machín, Lucía Antúnez. María Rosa Curutchet and Gastón Ares

\section{Behavioural nutrition}

Relationships between children's sugar consumption at home and their food choices and consumption at school lunch Khlood Baghlaf, Vanessa Muirhead and Cynthia Pine

A reply to 'Relationships between children's sugar consumption at home and their food choices and consumption at school lunch' Julia $R$ Jahansooz

A reply to 'Relationships Between Children's Sugar Consumption at Home and Their Food Choices and Consumption at School Lunch' Khlood Baghlaf

\section{Nutritional epidemiology}

Diet quality, nutrient intakes and biochemical status of New Zealand women of childbearing age according to alcohol consumption patterns Sherly Parackal, Claire Smith and Paula Skidmore

Preconception $\mathrm{Hb}$ concentration with risk of spontaneous abortion: a population-based cohort study in over 3.9 million women across rural China Qin Xu, Ying Yang, Fangchao Liu, Long Wang, Qiaomei Wang, Haiping Shen, Zongyu Xu, Yiping Zhang, Donghai Yan, Yuan He, Ya Zhang, Hongguang Zhang, Zuoqi Peng and $\mathrm{Xu} \mathrm{Ma}$

Maternal folic acid supplementation and more prominent birth weight gain in twin birth compared with singleton birth: a cross-sectional study in northwest China

Binyan Zhang, Suhang Shang, Shanshan Li, Baibing Mi, Minmin Li, Guoshuai Shi, Mao Ma, Qian Wang, Hong Yan and Shaonong Dang

\section{Community nutrition}

Parental depression and nutrition: findings from a cross-sectional household survey in Nepal Ramesh Prasad Adhikari, Ryoko Williamson, Thalia M Sparling, Elaine Ferguson and Kenda Cunningham
Addressing embodied inequities in health: how do we enable improvement in women's diet in pregnancy?

L McKerracher, S Oresnik, T Moffat, B Murray-Davis, J Vickers-Manzin,

L Zalot, D Williams, DM Sloboda and ME Barker

\section{Interventions}

Volunteers' experiences of providing telephone-based breast-feeding peer support in the RUBY randomised controlled trial

HA Grimes, TShafiei, HL McLachlan and DA Forster

\section{Public policies}

Changes to dietary and health outcomes

following implementation of the 2012

updated US Department of Agriculture

school nutrition standards: analysis

using National Health and Nutrition

Examination Survey, 2005-2016

Jenny Jia, Lynn L Moore, Howard Cabral,

Amresh Hanchate and Marc R LaRochelle

School meals matter: federal policy can improve children's nutrition and health

(Jia et al. 2020)

Lorrene D Ritchie

Sustainability

How to protect both health and food system sustainability? A holistic

'global health'-based approach via the

$3 \mathrm{~V}$ rule proposal

A Fardet and E Rock

\section{Workforce development}

Strengthening public health nutrition: findings from a situational assessment to inform system-wide capacity building in Ontario, Canada

Rachel JL Prowse, Sarah A Richmond,

Sarah Carsley, Heather Manson and Brent Moloughney

Cambridge Core For further information about this journal please go to the journal website at: cambridge.org/phn 